\title{
O Conhecimento da Abordagem Investigativa em Aulas de Matemática na Formação de Professores
}

\section{The Knowledge of the Investigative Approach in Mathematics Classes in Teacher Training}

\author{
Denise Knorst da Silva* \\ Universidade Federal da Fronteira Sul - (UFFS) \\ David Antônio da Costa** \\ Universidade Federal de Santa Catarina - (UFSC)
}

\begin{abstract}
Resumo
Esse estudo refere-se a uma pesquisa de doutorado que investiga mobilizações de conhecimento sobre a prática docente produzidas em uma ação de formação orientada por casos de ensino (MIZUKAMI, 2000, 2004) sobre a abordagem investigativa em aulas de Matemática. A ação ocorreu com um grupo de catorze professores do Ensino Fundamental de uma Escola da rede pública estadual do RS e foi organizada em dois momentos: i) análise de casos de ensino sobre a abordagem investigativa pelos professores; ii) planejamento e desenvolvimento de aula na abordagem investigativa pelos professores. A pesquisa de cunho qualitativo teve os dados produzidos a partir de gravações em áudio dos encontros de formação e de registros escritos dos professores, estes tomados para interpretação pela análise textual discursiva, segundo Moraes e Galiazzi (2006, 2011). As categorias de análise, a priori, foram organizadas em três direções: i) caracterização da abordagem investigativa, quanto aos seus elementos - tarefa investigativa, atividade Matemática investigativa, comunicação como diálogo; ii) reconhecimento da complexidade pedagógica da abordagem investigativa - atenção aos princípios balizadores para a compreensão da abordagem investigativa; iii) mobilização de conhecimentos matemáticos para o ensino - conforme proposto por Ball e colaboradores (2008). A síntese dos resultados sinaliza o potencial da ação de formação para a compreensão da abordagem investigativa pelos docentes e para a mobilização de conhecimentos matemáticos para o ensino. Além disso, a interpretação da análise, na busca do metatexto, aponta para a abordagem investigativa em aulas de Matemática como um conhecimento relevante à formação de professores.
\end{abstract}

Palavras-chave: Formação de Professores; Abordagem Investigativa; Casos de Ensino

\begin{abstract}
This study refers to a doctoral research that investigates mobilizations of knowledge about the teaching practice produced in a course-oriented training action (MIZUKAMI, 2000, 2004) on the investigative approach in mathematics classes. The action took place with a group of fourteen teachers from the Elementary School of a

\footnotetext{
* Mestre em Matemática pela Universidade Regional do Noroeste do Estado do RS (UNIJUÍ). Docente da Universidade Federal da Fronteira Sul (UFFS), Erechim, RS, Brasil. E-mail: denise.silva@uffs.edu.br.

** Doutor em Educação Matemática pela Pontífica Universidade Católica (PUC/SP). Professor do Programa de Pós-Graduação em Educação Científica e Tecnológica - PPGECT/UFSC, e-mail: david.costa@ufsc.br.
} 
public school in the state of Rio Grande do Sul and was organized in two moments: i) analysis of teaching cases about the investigative approach by teachers; ii) planning and developing a class in the investigative approach by teachers. The qualitative research had the data produced from audio recordings of the training meetings and written records of the teachers, which were taken for interpretation by discursive textual analysis, according to Moraes and Galiazzi (2006, 2011). The categories of analysis, a priori, were organized in three directions: i) characterization of the investigative approach, as to its elements - investigative task, investigative Mathematical activity, communication as dialogue; ii) recognition of the pedagogical complexity of the investigative approach - attention to the guiding principles for understanding the research approach; iii) mobilization of mathematical knowledge for teaching - as proposed by Ball et al. (2008). The synthesis of the results indicates the potential of the training action for the understanding of the investigative approach by the teachers and for the mobilization of mathematical knowledge for teaching. In addition, the interpretation of the analysis, in the metatext search, points to the investigative approach in Mathematics classes as a knowledge relevant to teacher training.

Keywords: Teacher training; Investigative Approach; Teaching Cases

\section{A Pesquisa Sobre A Abordagem Investigativa Na Formação De Professores}

Esse estudo refere-se a uma pesquisa de doutorado ${ }^{1}$ cuja investigação se dá sobre uma ação de formação de professores e suas possibilidades para a compreensão da abordagem investigativa em aulas de Matemática ${ }^{2}$ e para a mobilização de conhecimentos sobre a prática docente. As expectativas se voltam para o avanço na integração de metodologias investigativas $^{3}$ na prática do professor de Matemática da Educação Básica.

A problemática sobre a abordagem investigativa é oriunda da prática com metodologias investigativas na formação de professores, cujo processo reflexivo sinaliza para a necessidade de investigar as dificuldades de integração dessas metodologias na prática docente. A hipótese é que compreensões sobre a complexidade pedagógica associada a esse fazer, mediante um processo com características próprias e norteado por elementos e princípios balizadores da sua compreensão - a abordagem investigativa -, possam contribuir com a integração dessas metodologias investigativas na prática docente.

Essa abordagem, então, é defendida como um construto teórico norteador da prática docente quando a intencionalidade é utilizar metodologias investigativas - construto teóricoprático - sendo construída sob duas vias: a primeira, no sentido da sua caracterização quanto aos elementos norteadores da prática; e a segunda, quanto aos princípios balizadores da ação

\footnotetext{
${ }^{1} \mathrm{O}$ processo formativo de doutoramento é da autora, denominada pesquisadora nesse texto, sob orientação do autor, na modalidade DINTER UFFS/UFSC, no PPGECT - Programa de Pós-Graduação em Educação Científica e Tecnológica. O processo é desenvolvido com o apoio da CAPES.

${ }^{2}$ Considerando o elevado número de vezes que a expressão "abordagem investigativa em aulas de Matemática" é utilizada no texto será simplificada por "abordagem investigativa".

${ }^{3}$ As metodologias investigativas envolvem, na pesquisa e nesse texto, as metodologias de ensino de Matemática (ou estratégias/possibilidades/tendências) pautadas na investigação: as investigações matemáticas, a modelagem matemática, a resolução de problemas, os projetos, entre outras.
} 
de formação de professores para a compreensão da abordagem investigativa em aulas de Matemática.

A partir da construção teórica, a busca é por uma ação de formação que promova a compreensão da abordagem investigativa pelos professores. Nessa busca, uma significativa contribuição foi encontrada nos casos de ensino, tendo como principal fonte os estudos de Maria da Graça Mizukami, pesquisadora, que por sua vez faz uso da teoria defendida por Lee Shulman.

As contribuições de Shulman (1996), na perspectiva de casos de ensino, é de que estimulam a reflexão sobre episódios escolares e a narração de histórias percursos e que tem possibilitado a promoção da aprendizagem e o desenvolvimento profissional da docência. Nas palavras de Shulman:

Nós não aprendemos a partir da experiência; nós aprendemos pensando sobre nossa experiência (...) Um caso toma material bruto da experiência primeira ordem e coloca-a narrativamente em experiência de segunda ordem. Um caso é uma versão relembrada, recordada, reexperienciada, o refletido de uma experiência direta. $\mathrm{O}$ processo de relembrar, recontar, reviver e refletir é o processo de aprender pela experiência (SHULMAN, 1996, p. 208).

Os casos de ensino, em consonância com os referenciais de Mizukami (2000, 2004), são tomados como instrumento de reflexão da prática pedagógica que, por suas características, permitem que os professores vivenciem processos formativos que conduzam a aprendizagem e o desenvolvimento profissional da docência. Nessa perspectiva a autora destaca que:

É instrumento pedagógico que pode ser usado para ajudar os professores na prática de processos de análise, resolução de problemas e tomadas de decisões, entre outros processos profissionais básicos. Os casos de ensino são importantes para o desenvolvimento de estruturas de conhecimento que capacitem os professores a reconhecer eventos novos, a compreendê-los e a delinear formas sensíveis e educativas de ação (MIZUKAMI, 2000, p. 153).

Essa ação de formação foi organizada na modalidade de curso de formação continuada e desenvolvida com um grupo de professores do Ensino Fundamental de uma Escola da rede estadual de ensino do RS, gerando um processo formativo permeado por reflexões e discussões. Os registros desse processo ocorreram pela transcrição de falas dos professores e da pesquisadora, gravadas em áudios em cada encontro do grupo, sendo tomados para análise em duas direções: a primeira, para a análise das possibilidades da ação de formação desenvolvida quanto à compreensão da abordagem investigativa em aulas de Matemática 
pelos professores do grupo; e, a segunda, para a análise acerca das reflexões e mobilizações de conhecimentos matemáticos para o ensino. Esse processo foi pautado metodologicamente pela análise textual discursiva, segundo as contribuições de Moraes e Galiazzi (2006).

Esse estudo explicita a abordagem investigativa, enquanto construto teórico-prático para a formação de professores, a análise da ação elaborada e desenvolvida com vistas à sua compreensão por um grupo de professores e os resultados da pesquisa em contribuição com a integração de metodologias investigativas no Ensino de Matemática.

\section{A Abordagem Investigativa Em Aulas De Matemática}

A reflexão sobre a relevância do construto teórico-prático abordagem investigativa pode ser estimulada pela questão: Qual a abordagem de ensino adotada pelo professor ao utilizar metodologias investigativas em aulas de Matemática e que influência exerce na/para a integração de tais metodologias na prática? A hipótese é de que há necessidade de uma abordagem específica associada à prática com metodologias investigativas e que a construção dessa compreensão exige ações específicas na formação de professores. $\mathrm{O}$ entendimento é que a adoção da abordagem investigativa não está diretamente relacionada ao fazer uso de metodologias investigativas em cursos de formação de professores e de que essa abordagem, se compreendida, pode contribuir com a integração dessas metodologias na prática docente do professor de Matemática.

Nesse contexto, a abordagem investigativa pode ser um referencial orientador da prática do professor que se propõe a utilizar metodologias investigativas para ensinar Matemática, constituindo-se de elementos teóricos e princípios balizadores da ação de formação de professores que visa à compreensão da complexidade pedagógica associada ao uso de tais metodologias.

A definição dos elementos nasce da reflexão sobre a prática na formação de professores, da formadora-pesquisadora, sobre "o que" é relevante enquanto orientação ao professor para a utilização de metodologias investigativas, num olhar sobre as implicações, possibilidades e complexidade associadas à esse fazer.

Assim, a definição dos elementos, oriunda da prática com metodologias investigativas na formação de professores e da fundamentação em referenciais relacionados às investigações matemáticas e à aprendizagem em Educação Matemática (PONTE et al., 1998; PONTE et al., 2003; ALRO e SKOVSMOSE, 2006), não tem a pretensão de uma caracterização inédita, mas 
sim, a busca do construto teórico-prático da abordagem investigativa. Os elementos se colocam como orientadores da prática docente e da ação de formação, esse é o propósito do olhar reflexivo sobre o fazer investigativo:

i) tarefas investigativas, entendidas como situações ou problemas abertos, por isso menos estruturados e que permitem a resolução por diferentes caminhos, na busca por uma das suas soluções;

ii) atividade matemática investigativa, conjunto de processos mobilizados pelo aluno para a aprendizagem pelo fazer e pensar matematicamente, que envolve investigar relações e elaborar questionamentos, pela conjecturação, argumentação e fundamentação de ideias e conclusões;

iii) comunicação como diálogo, em que prevalecem atos dialógicos como forma de interação entre professor e alunos, engajados em um processo que visa à aprendizagem e que por isso valoriza a participação ativa do aluno, compartilhando e discutindo ideias.

Nessa direção, a prática do professor de Matemática que adota a abordagem investigativa é constituída por tarefas investigativas que promovem o desenvolvimento da atividade matemática investigativa pelo aluno e que possam estabelecer uma comunicação na perspectiva do diálogo entre professor e alunos.

A compreensão dessa abordagem pelo professor, em suas características, exige uma ação de formação pautada sobre princípios balizadores capazes de promover reflexões sobre a prática - a segunda via do construto teórico-prático. A construção desses princípios balizadores também considera aspectos legitimados pela prática e pela reflexão sobre ela, provenientes de ações da pesquisadora na formação de professores. Esses aspectos traduzemse nos seguintes princípios:

I- o professor de Matemática, ou futuro professor, em processo de formação, quando convidado a utilizar uma metodologia de ensino, "nova" para ele ou não, investigativa ou não, a utiliza na mesma concepção de ser professor de Matemática que defende/construiu. A questão que se coloca é a influência dessa concepção de ensinar e aprender Matemática sobre a prática desse professor;

II- os passos/momentos/fases que constituem a metodologia de ensino, durante o processo de formação, de algum modo são o foco da atenção do professor (aprendizagem), direcionando a ênfase de ações de formação para o "como fazer"; dessa forma, o "porque fazer" e "para que fazer", no sentido de entender os propósitos da abordagem investigativa, ainda precisam de um espaço específico na formação. 
III- a postura do professor, conduzindo o processo de ensino e orientando a aprendizagem, assumindo determinados papéis na interação com os alunos tende a não sofrer mudanças ainda que diante de metodologias investigativas, ou seja, muitas vezes o professor muda de metodologia sem mudar de postura ou possibilitar mudança na participação do aluno. $\mathrm{O}$ questionamento é sobre o papel dos sujeitos no processo de ensino e de aprendizagem e a necessária postura investigativa do professor e dos alunos em atenção a determinados propósitos educacionais;

IV- a organização da sala de aula - tempos, orientações, questionamentos, sistematizações, formalizações, avaliação - se apresentam sob nova perspectiva na utilização de metodologias investigativas, no entanto sua relevância muitas vezes não é reconhecida pelo professor ou, quando reconhecida, é de difícil condução. A atenção ao aspecto da gestão investigativa do trabalho pedagógico coloca-se como uma questão relevante;

V- a forma de avaliação, no contexto de metodologias investigativas, sofre questionamentos em ações de formação de professores, com manifestações acerca de como realizar uma avaliação na perspectiva investigativa.

Esses aspectos se constituem num caminho para o planejamento da ação de formação que visa à compreensão da abordagem investigativa, ou seja, o construto teórico-prático abordagem investigativa é norteador da ação de formação de professores quanto aos elementos que caracterizam a prática do professor e quanto aos princípios a serem mobilizados de forma reflexiva para a compreensão dessa abordagem. Nesse sentido, a intencionalidade é contribuir com o processo de integração de metodologias investigativas no ensino de Matemática, mediante a investigação sobre a abordagem investigativa.

\section{A Ação De Formação De Professores Na Abordagem Investigativa}

A partir da caracterização da abordagem investigativa se dá a organização da ação de formação capaz de promover a compreensão dessa abordagem pelos professores a partir dos princípios balizadores, anteriormente definidos. A organização foi pautada em dois momentos: momento I - de análise de casos de ensino elaborados pela pesquisadora; momento II - aulas na abordagem investigativa, com a elaboração e o desenvolvimento de propostas pelos professores participantes da formação. A ação ocorreu no período de abril a setembro de 2018, com um grupo de catorze professores do ensino fundamental da Escola Estadual de Ensino Médio Irany Jaime Farina, do município de Erechim, no estado do Rio Grande do Sul. 
Os professores participantes apresentam diferentes características quanto à formação e atuação no ensino fundamental, sendo cinco professores atuantes nos anos iniciais, oito professores com formações em diferentes áreas do conhecimento com atuação nos anos finais e uma professora atuante nos anos iniciais e finais.

Os encontros e respectivas atividades estão detalhados no quadro abaixo:

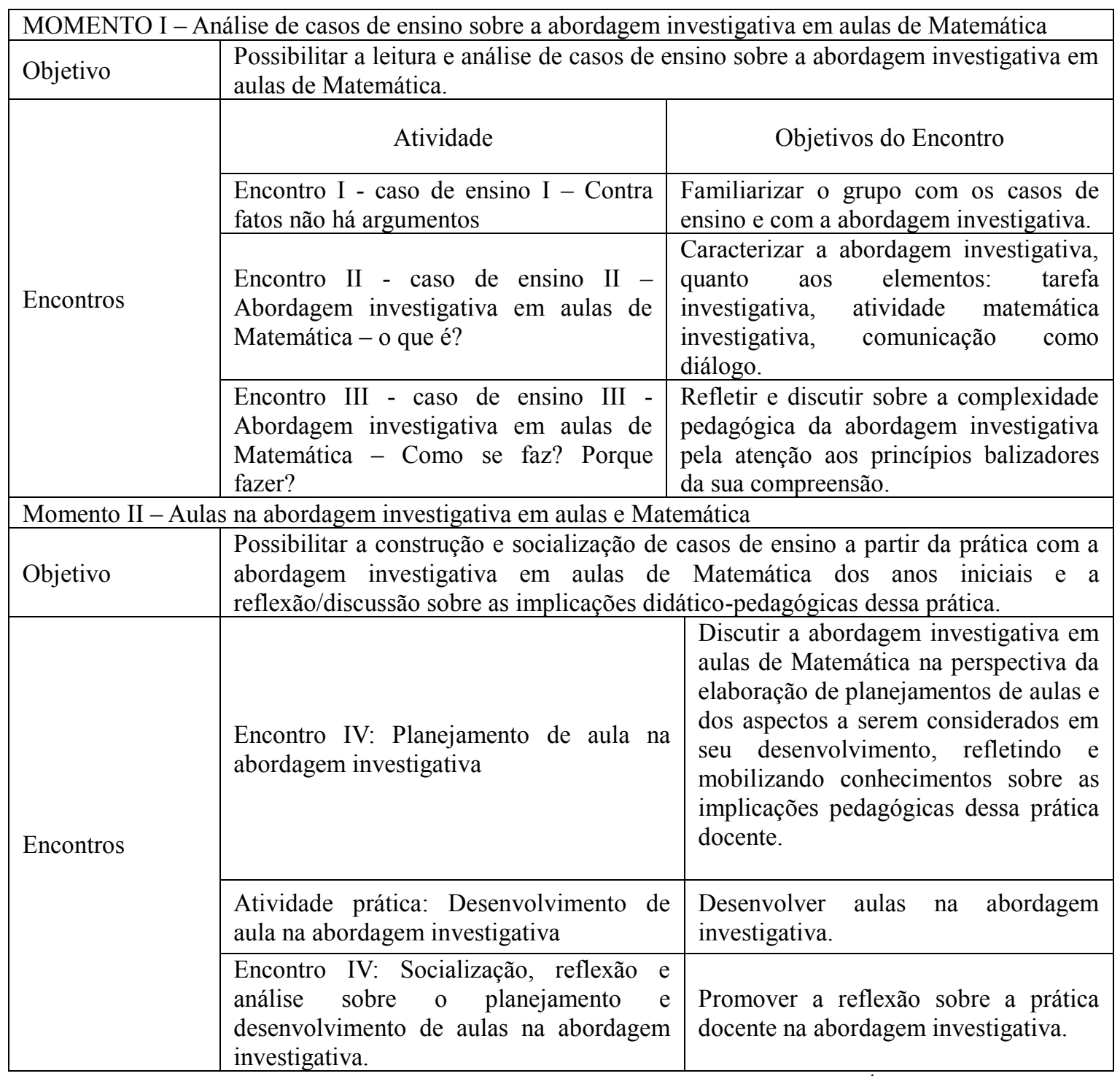

Quadro 1 - Organização da ação de formação de professores ${ }^{4}$

Fonte: Elaborado pelos autores

O recorte, nesse estudo, é para a análise das reflexões produzidas na ação de formação de professores, que ocorre em três direções: i) caracterização da abordagem investigativa, quanto aos seus elementos - tarefa investigativa, atividade Matemática investigativa,

\footnotetext{
${ }^{4} \mathrm{O}$ detalhamento da ação, os casos de ensino e os resultados da análise dos dados coletados estão registrados em Silva (2018, no prelo).
} 
comunicação como diálogo; ii) reconhecimento da complexidade pedagógica da abordagem investigativa - atenção aos princípios balizadores para a compreensão da abordagem investigativa; iii) mobilização de conhecimentos matemáticos para o ensino - conforme proposto por Ball e colaboradores (2008): conhecimento comum do conteúdo; conhecimento especializado do conteúdo; conhecimento do conteúdo e dos alunos; conhecimento do conteúdo e do ensino.

\section{Reflexões E Conhecimentos Sobre A Abordagem Investigativa Na Ação De Formação De Professores}

A compreensão da abordagem investigativa pelos professores foi analisada considerando os elementos e princípios balizadores desse construto teórico-prático, ou seja, tendo a ação de formação sido orientada pela abordagem investigativa, os dados obtidos dos encontros foram tomados para a análise quanto a aproximação com as características desse construto (elementos) e quanto a atenção aos princípios balizadores da sua compreensão.

A caracterização da abordagem investigativa se constrói na análise dos casos de ensino quando o professor diferencia as tarefas investigativas por seu potencial para a atividade Matemática, de estímulo ao pensar e fazer matemática pelo aluno, numa forma de comunicação que valoriza a partilha de ideias entre os sujeitos, estabelecendo o diálogo para a aprendizagem.

O quadro 2 evidencia o caráter das reflexões e conhecimentos dos professores relacionados a caracterização da abordagem investigativa, estes revelados na ação de formação de professores:

\begin{tabular}{|c|c|c|}
\hline Tarefa investigativa & $\begin{array}{l}\text { Atividade Matemática } \\
\text { Investigativa }\end{array}$ & Comunicação pelo diálogo \\
\hline $\begin{array}{l}\text { - diferenças metodológicas, } \\
\text { comparação com práticas de sala } \\
\text { de aula; } \\
\text { - oposição/contraste com o } \\
\text { ensino tradicional; } \\
\text { - ruptura com a ideologia da } \\
\text { certeza; } \\
\text { - reflexão sobre a aprendizagem } \\
\text { da Matemática pelos alunos; } \\
\text { - o conteúdo na prática com } \\
\text { tarefas investigativas; } \\
\text { - reconhecidas como } \\
\text { interessantes e prazerosas } \\
\text { - questões com inúmeras } \\
\text { possibilidades, mais de uma }\end{array}$ & $\begin{array}{l}\text { - possibilidades de promover o } \\
\text { pensar; } \\
\text { - cálculo mental; } \\
\text { - valorização e possibilidade de } \\
\text { construção do conhecimento } \\
\text { pelos alunos; } \\
\text { - desenvolvimento da capacidade } \\
\text { de interpretação dos alunos; } \\
\text { - estímulo ao pensar e fazer } \\
\text { matemática; } \\
\text { - busca de estratégias pelo aluno; } \\
\text { - levantar hipóteses } \\
\text { - participação do aluno no } \\
\text { processo de aprendizagem; } \\
\text { - construção do conhecimento; }\end{array}$ & $\begin{array}{l}\text { - postura investigativa do } \\
\text { professor; } \\
\text { - troca de saberes; } \\
\text { - valorização do trabalho em } \\
\text { grupo; } \\
\text { - importância da socialização; } \\
\text { - participação do aluno, } \\
\text { valorização de suas falas e } \\
\text { mobilização de conhecimentos } \\
\text { prévios; } \\
\text { - aluno ativo e protagonista; } \\
\text { - nova comunicação entre os } \\
\text { sujeitos; } \\
\text { - professor deixa de ser } \\
\text { centralizador da fala; }\end{array}$ \\
\hline
\end{tabular}




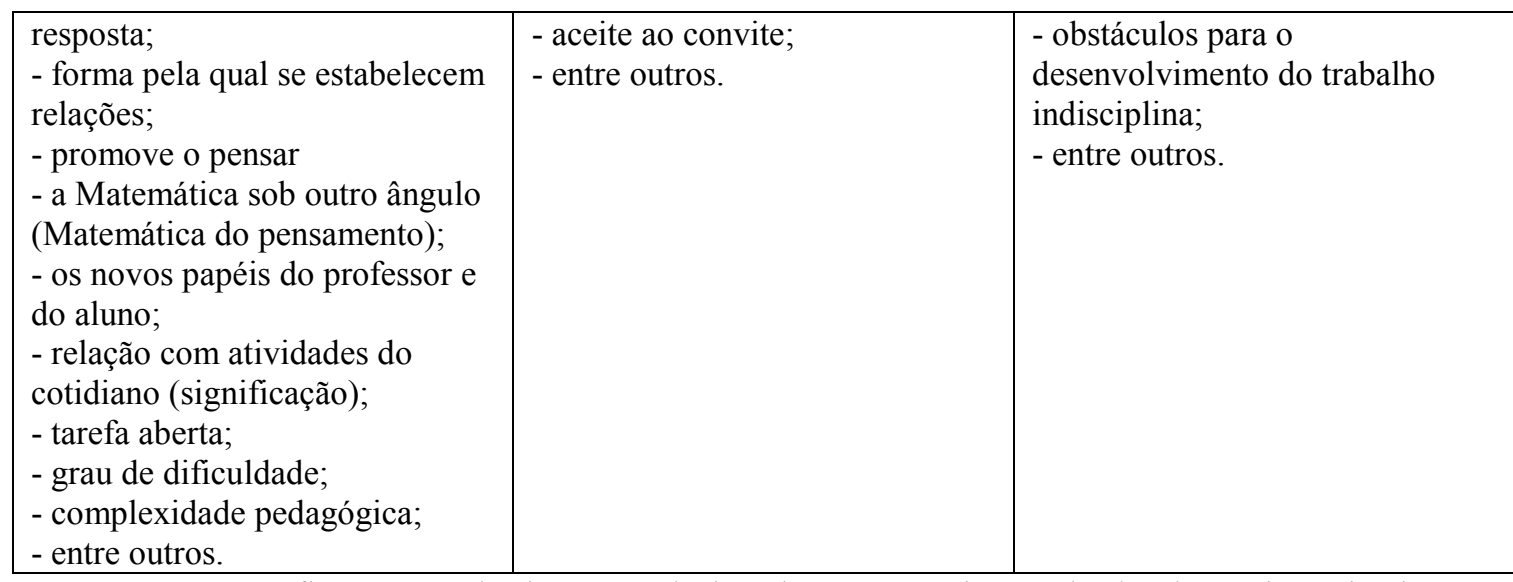

Quadro 2 - Reflexões e conhecimentos relacionados à caracterização da abordagem investigativa Fonte: Elaboração da pesquisadora a partir dos dados da pesquisa

As sistematizações apontadas no quadro evidenciam que o professor reconhece as características do construto abordagem investigativa a medida que utiliza termos relacionados aos elementos, ou os próprios elementos, para designar a forma com que o processo de ensino e de aprendizagem ocorre sob influência dessa abordagem.

A complexidade pedagógica da abordagem investigativa é compreendida pelos professores à medida que a atenção se volta para os princípios balizadores da formação. Essa atenção é sinalizada em alguns aspectos, registrados no quadro 3:

\begin{tabular}{|c|c|}
\hline Princípios & Alguns aspectos analisados na ação de formação \\
\hline $\begin{array}{l}\text { Concepções de } \\
\text { ensinar e aprender } \\
\text { Matemática }\end{array}$ & $\begin{array}{l}\text { - questionamento sobre as formas de ensinar e fatores que influenciam na } \\
\text { escolha metodológica; } \\
\text { - relato de experiências e análise de episódios de sala de aula, reflexão sobre } \\
\text { ações; } \\
\text { - há reconhecimento da viabilidade de integração a abordagem investigativa; } \\
\text { - relação da abordagem investigativa com a contextualização e } \\
\text { interdisciplinaridade, já integrantes das concepções de ensino e a aprendizagem } \\
\text { do professor; } \\
\text { - exercício reflexivo do professor; } \\
\text { - etc. }\end{array}$ \\
\hline $\begin{array}{l}\text { Gestão investigativa } \\
\text { do trabalho } \\
\text { pedagógico }\end{array}$ & $\begin{array}{l}\text { - necessidade de tomar decisões; } \\
\text { - importância do aceite ao convite; } \\
\text { - imprevisibilidade da prática com tarefas investigativas } \\
\text { - caracterização das tarefas investigativas } \\
\text { - implicações pedagógicas da abordagem investigativa: tempo, resistências, } \\
\text { conduções, etc. } \\
\text { - a relevância do planejamento do professor; } \\
\text { - etc. }\end{array}$ \\
\hline $\begin{array}{l}\text { Propósitos da } \\
\text { abordagem } \\
\text { investigativa }\end{array}$ & $\begin{array}{l}\text { - conexões entre conteúdos na abordagem investigativa; } \\
\text { - clareza das implicações das referências (matemática pura, realidade e } \\
\text { semirealidade) na elaboração das tarefas; } \\
\text { - estímulo ao pensar e ao fazer Matemática } \\
\text { - comparações entre metodologias de ensino e suas implicações } \\
\text { - atividade Matemática investigativa: levantar hipóteses, questionar, buscar } \\
\text { caminhos para a resolução, argumentar e partilhar ideias; } \\
\text { - etc. }\end{array}$ \\
\hline $\begin{array}{l}\text { Posturas } \\
\text { investigativas dos }\end{array}$ & $\begin{array}{l}\text { - reflexão, análise e reconhecimento de diferentes papéis do professor; } \\
\text { - relevância da mediação do professor com questionamentos; }\end{array}$ \\
\hline
\end{tabular}




\begin{tabular}{|l|l|}
\hline sujeitos & - a importância dos grupos de trabalho; \\
& - a vigilância pedagógica para a adoção de posturas adequadas pelo professor; \\
& - incentivo e necessidade da participação do aluno; \\
& - partilha de ideias; \\
& - o papel ativo do aluno, com conhecimentos prévios, no sentido de "dar voz" à \\
& ele; \\
& - necessidade de novas posturas integra o discurso do professor; \\
& - etc. \\
\hline & - reconhecimento de que a aprendizagem do aluno se dá sobre conteúdos \\
& atitudinais, conceituais e procedimentais; \\
Avaliação na & - abordagem investigativa como potencializadora da criatividade, da autoestima \\
perspectiva & e autonomia dos alunos; \\
investigativa & - diferentes momentos e possibilidades de acompanhar e verificar a \\
& aprendizagem do aluno; \\
& - avaliação do aluno (aprendizagem) e pelo professor (ensino), potencializada \\
pela prática reflexiva; & - etc. \\
\hline
\end{tabular}

Quadro 3 - Reconhecimento da complexidade pedagógica da abordagem investigativa Fonte: Elaboração da pesquisadora a partir dos dados da pesquisa

Os aspectos indicados, que integraram os diálogos e reflexões nos encontros da ação de formação, tem sua ênfase sobre: a relevância de (re)elaborar a concepção de ensinar e aprender Matemática; a especificidade da gestão da sala de aula ao pretender que seja investigativa; a diferença de propósitos de ensino quanto a abordagem e a relevância dessa clareza para a prática docente; a influência das posturas dos sujeitos nos processos de ensino e de aprendizagem; as possibilidades quanto a avaliação, formas e consequências, na perspectiva investigativa. Nesse sentido, a complexidade pedagógica da abordagem investigativa é discutida e compreendida pelos docentes no processo de formação.

Além da caracterização da abordagem investigativa e do reconhecimento da sua complexidade pedagógica, a ação de formação é analisada na perspectiva da mobilização de conhecimentos matemáticos para o ensino, nos pressupostos de Ball e seus colaboradores (2008). Os estudos de Ball e colaboradores, fundamentados na elaboração teórica de Shulman (1986), referem-se a noção de Mathematical Knowledge for Teaching (MKT) Conhecimento Matemático para o Ensino. Segundo Ball, Thames e Phelps (2008), a introdução do termo conhecimento pedagógico do conteúdo (SHULMAN, 1986) sugere a necessidade de um conhecimento do conteúdo que é exclusivo para o ensino, numa ligação entre o conhecimento do conteúdo e a prática de ensino.

Nessa direção, os autores definiram o conhecimento matemático dos professores para o ensino como o conhecimento matemático necessário para realizar as tarefas recorrentes de ensinar matemática para os alunos. Os argumentos para a ampliação da ideia originalmente proposta por Shulman é de que existe uma forma de conhecimento matemático específico para o ensino, sendo necessário, mas não suficiente, aos professores saber/conhecer o assunto 
(conteúdo) que ensinam, mas também uma preparação/formação para conhecerem e ser capazes de usar a matemática que é necessária no trabalho de ensinar.

Com isso, Ball, Thames e Phelps (2008) conjeturam que (1) o conhecimento do conteúdo (SHULMAN, 1986) poderia ser subdividido em conhecimento comum do conteúdo e conhecimento especializado do conteúdo; (2) o conhecimento pedagógico do conteúdo (SHULMAN, 1986) poderia ser subdividido em conhecimento do conteúdo e de estudantes ${ }^{5}$ e conhecimento do conteúdo e de ensino.

De forma resumida, esses conhecimentos podem ser exemplificados por: reconhecer uma resposta errada é um conhecimento comum do conteúdo; dimensionar rapidamente a natureza de um erro, especialmente aqueles que não são familiares, é um conhecimento especializado do conteúdo; ter familiaridade com os erros comuns e saber por que diversos alunos os cometem é um conhecimento de conteúdo e de estudantes; selecionar uma abordagem de ensino que seja eficiente para superar certas dificuldades e/ou explorar certos aspectos de um conteúdo é um conhecimento do conteúdo e de seu ensino.

Nesse estudo, os conhecimentos matemáticos para o ensino, de Ball e colaboradores (2008), são tomados para a análise dos dados produzidos na ação de formação, com o propósito de investigar as suas possibilidades para a mobilização de conhecimentos sobre a prática docente.

O conhecimento comum do conteúdo na ação de formação se caracteriza como elemento determinante em duas direções: i) um amplo domínio do conteúdo Matemático coloca-se como fundamental na escolha, no planejamento e desenvolvimento de tarefas investigativas; ii) a aprendizagem do conteúdo Matemático pelo aluno é o objetivo do ensino também numa abordagem investigativa em aulas de Matemática.

O conhecimento especializado do conteúdo é mobilizado pelos professores quando consideram o conteúdo Matemático, que relaciona e que aborda nas reflexões e análises sobre os casos de ensino, na perspectiva de como será o seu ensino, ou seja, extrapola a ação de colocar-se em investigação para compreender as relações e conteúdos ali presentes para projetar o planejamento e a ação de ensinar, refletir sobre como organizar e desenvolver o ensino do conteúdo com tarefas investigativas. Essa perspectiva envolve as escolhas para o planejamento, as decisões no desenvolvimento e as retomadas e modificações diante de reflexões e avaliações, entre outras.

\footnotetext{
${ }^{5}$ Nesse texto o conhecimento do conteúdo e dos estudantes é expresso por conhecimento do conteúdo e dos alunos, uma vez que o termo "alunos" é usado para outras referências à esse sujeito na pesquisa.
} 
O conhecimento do conteúdo e dos alunos envolve a capacidade de interpretação de como pensam, o que acharão confuso, a familiaridade com a linguagem matemática. Na ação de formação, os professores revelam esse conhecimento quando dialogam sobre a relevância de acompanhar e conhecer o fazer e o pensar matemático do aluno, sobre seus conhecimentos prévios, as estratégias apresentadas, como está familiarizado com as tarefas investigativas, entre outras. Os diálogos que mobilizam tais conhecimentos se referem a participação do aluno na atividade, assumindo papéis e posturas que o colocam como sujeito ativo, que revela formas de agir, pensar e fazer, e que necessitam do professor formas específicas de ensinar, esse movimento envolve o fazer matemática pelo aluno com a mediação e condução necessários a uma abordagem investigativa.

O conhecimento do conteúdo e do ensino combina o conhecimento sobre ensinar e conhecimento sobre matemática, formas de representações e de contribuições que diferentes métodos e procedimentos proporcionam para a aprendizagem, relaciona-se à condução de propostas de ensino, a reflexão e análise, adequação de estratégias, entre outras. As reflexões e análises dos professores referem-se a necessidade de tomada de decisão sobre a tarefa de investigação, quais conceitos abordar, quais poderão surgir, qual a ênfase, a valorização das contribuições dos alunos, o tempo pedagógico para cada momento da atividade investigativa, a sistematização do processo e formalização de conceitos, etc.

No quadro 4 são apresentados alguns aspectos analisados na ação de formação como indicadores da mobilização dos conhecimentos matemáticos para o ensino:

\begin{tabular}{|c|c|}
\hline $\begin{array}{l}\text { Conhecimentos } \\
\text { Matemáticos para o ensino }\end{array}$ & Aspectos mobilizadores dos conhecimentos na ação de formação \\
\hline $\begin{array}{l}\text { Conhecimento comum do } \\
\text { conteúdo }\end{array}$ & $\begin{array}{l}\text { - olhar "de professor" sobre as tarefas apresentadas nos casos de ensino; } \\
\text { - investigação propriamente dita sobre as tarefas e projeção ao contexto } \\
\text { da aula de Matemática; } \\
\text { - relevância do planejamento para a abordagem investigativa, incluindo o } \\
\text { domínio dos conceitos matemáticos; } \\
\text { - reconhecimento da imprevisibilidade associada a abordagem } \\
\text { investigativa, implicada na preparação do professor; } \\
\text { - etc. }\end{array}$ \\
\hline $\begin{array}{l}\text { Conhecimento especializado } \\
\text { do conteúdo }\end{array}$ & $\begin{array}{l}\text { - reconhecimento e preparação para a conexão entre conteúdos, } \\
\text { potencializada na abordagem investigativa; } \\
\text { - caráter aberto da abordagem investigativa implicando em uma } \\
\text { condução com especificidades próprias; } \\
\text { - (re)elaboração de concepções sobre ensinar e aprender matemática, } \\
\text { questionando-as; } \\
\text { - questionamento sobre a abordagem do conteúdo em aulas de } \\
\text { Matemática. }\end{array}$ \\
\hline $\begin{array}{l}\text { Conhecimento do conteúdo } \\
\text { e do aluno }\end{array}$ & $\begin{array}{l}\text { - reconhecimento do papel do aluno ao colocar-se em atividade } \\
\text { matemática; } \\
\text { - relevância da comunicação como diálogo; } \\
\text { - socialização e aprendizagem em interação com o outro; } \\
\text { - a intencionalidade das tarefas abertas para a participação ativa do aluno; } \\
\text { - o aceite ao convite e o movimento necessário para isso; }\end{array}$ \\
\hline
\end{tabular}




\begin{tabular}{|l|l|}
\hline \multirow{5}{*}{ Conhecimento do conteúdo } & - o incentivo e a importância da postura investigativa; \\
\hline & - etc. \\
\hline e do ensímulo ao cálculo mental como uma perspectiva das tarefas \\
investigativas; \\
- questionamentos e comparações entre as formas de ensinar que são \\
habituais na sala de aula; \\
- implicações pedagógicas da tarefa investigativa; \\
- reflexões sobre o contexto escolar e a possibilidade de integração da \\
abordagem investigativa; \\
- necessidade de preparação do professor e o papel da formação de \\
- compreensão da abordagem investigativa em aulas de Matemática, \\
pautando as possibilidades de integração na prática; \\
- postura investigativa do professor, ilustrando possibilidades e \\
discutindo os propósitos. \\
- a necessidade de um processo reflexivo do professor; \\
- as possibilidades de aprendizagem num processo de ensino pautado na \\
abordagem investigativa e as possibilidades de avaliação do aluno em \\
coerência com essa abordagem; \\
- etc.
\end{tabular}

Quadro 4 - Mobilização dos conhecimentos matemáticos para o ensino na ação de formação Fonte: Elaboração da pesquisadora a partir dos dados da pesquisa

A ação de formação de professores orientada por casos de ensino sobre a abordagem investigativa gerou dados cuja análise sinaliza o potencial do construto teórico-prático para a mobilização de conhecimentos matemáticos para o ensino, já defendidos por Ball e seus colaboradores. As reflexões dos professores se associam ao conhecimento comum do conteúdo, ao conhecimento especializado do conteúdo, ao conhecimento do conteúdo e dos alunos e ao conhecimento do conteúdo e do ensino. A análise sinaliza para a contribuição da ação de formação com casos de ensino sobre a abordagem investigativa para a construção de conhecimentos matemáticos para o ensino.

\section{O Conhecimento Da Abordagem Investigativa Na Formação De Professores}

A especificidade da ação de formação de professores sobre a abordagem investigativa suscita o seu potencial para a sua compreensão e para a mobilização de conhecimentos matemáticos para o ensino, conforme classificação apontada por Ball e colaboradores. O olhar sobre essa análise, na busca de uma nova compreensão, reverbera que o conhecimento da abordagem investigativa tem relevância e potencial à formação de professores.

Nessa direção, aos conhecimentos matemáticos para o ensino sinaliza-se a relevância de agregar o conhecimento da abordagem investigativa. Tal conhecimento pode integrar, na classificação de Ball e seus colaboradores, a categoria do conhecimento do conteúdo e do ensino ou ainda caracterizar uma nova categoria. A classificação desse conhecimento não é o 
ponto em questão, mas sim a ênfase sobre esse conhecimento na formação de professores, uma vez que as análises indicam sua contribuição para o desenvolvimento profissional docente e o exercício do professor reflexivo.

Essa interpretação se justifica em pontos revelados na perspectiva da formação de professores sobre o construto teórico-prático da abordagem investigativa em aulas de Matemática, a saber:

- A abordagem investigativa evidencia a reflexão como aspecto essencial à formação e potencializa o exercício reflexivo docente (professor e formador);

- A abordagem investigativa promove a reflexão do professor sobre a sua prática, orientada por princípios balizadores;

- A abordagem investigativa, norteadora de ações formativas, promove o exercício reflexivo do formador de professores;

- A abordagem investigativa é uma referência na formação de professores e para a prática docente, ou seja, coloca-se como orientadora das ações do formador e objetivo da formação;

- A abordagem investigativa gera um movimento de vigilância pedagógica para a integração dessa abordagem na prática docente, especialmente, quanto a adoção de posturas investigativas;

- A abordagem investigativa coloca professores e formador na posição de aprendiz, pela vigilância pedagógica e o processo gradativo de adoção de posturas investigativas;

- A abordagem investigativa gera valorização do trabalho colaborativo e cooperativo pela percepção de que grupos de apoio e diálogo são fundamentais à integração de propostas;

- A abordagem investigativa promove a crítica dos professores sobre a sua prática;

- A abordagem investigativa coloca o professor com um papel de protagonista da sua formação, uma vez que a toma para reflexão, problematiza e sinaliza/integra propostas;

- A abordagem investigativa na formação promove uma participação docente com olhares sobre o seu papel no desenvolvimento de tarefas.

A par das colocações, está a defesa do conhecimento da abordagem investigativa em aulas de Matemática para a formação de professores. A mobilização desse conhecimento favorece a constituição de um professor reflexivo, mais autônomo e capaz de tomar decisões conscientes; promove compreensões e sinaliza ações para a integração de metodologias investigativas na prática docente; contribui para qualificar a formação, atuação e desenvolvimento profissional. 


\section{Considerações}

O estudo traz contribuições de uma investigação no contexto de formação continuada num processo orientado por casos de ensino sobre a abordagem investigativa. Os resultados confirmam a abordagem investigativa como um construto teórico-prático orientador de ações de formação que visam a integração de metodologias investigativas no ensino de Matemática e para a mobilização de conhecimentos matemáticos para o ensino. Essa contribuição sinaliza para o conhecimento sobre a abordagem investigativa como relevante à formação de professores.

Nessa direção, a pesquisa contribui com a Educação Matemática no âmbito da investigação sobre processos formativos com casos de ensino e sobre práticas docentes na abordagem investigativa. A par dos resultados, há que se ter presente o processo inicial de pesquisa sobre essa abordagem, o que suscita o convite à ampliação dos estudos, práticas e construção epistemológica.

\section{Referências}

ALRO, H; SKOVSMOSE, O. Diálogo e Aprendizagem em Educação Matemática. Tradução de: Orlando Figueiredo. Belo Horizonte: Autêntica, 2006.

BALL, D. L.; THAMES, M. H.; PHELPS, G. Content knowledge for teaching: What makes it special? Journal of Teacher Education, New York, v. 59, n. 5, p. 389 - 407, nov./dez. 2008.

MIZUKAMI, M.G.N. Aprendizagem da Docência: algumas contribuições de L.S. Shulman. Revista do Centro de Educação da UFSM, v. 29, n.02, 2004. Disponível em: https://periodicos.ufsm.br/reveducacao/article/view/3838. Acesso em: 16 de agosto de 2017.

MIZUKAMI, M.G.N. Casos de ensino e aprendizagem profissional da docência. In: ABRAMOWICZ, A; MELLO, R.R. (Org.). Educação: pesquisa e práticas. Campinas, SP: Papirus, 2000, p. 139-161

MORAES, R; GALIAZZI, M. C. (2006). Análise textual discursiva: processo construído de múltiplas faces. Ciência \& Educação, v.12, n.1, p.117-128.

MORAES, R; GALIAZZI, M. C. Análise Textual Discursiva. Ijuí: Editora Unijuí, 2011.

PONTE, J. P.; FERREIRA, C.; VARANDAS, J.M.; BRUNHEIRA, L.; OLIVEIRA, H. A relação professor-aluno na realização de investigações matemáticas. Lisboa: Projecto MPT e APM, 1998.

PONTE, J. P; BROCARDO, J; OLIVEIRA, H. Investigações matemáticas na sala de aula. Belo Horizonte: Autêntica, 2003.

SHULMAN, L.S. Those Who Undersland: Knowledge growth in teaching. Educational Researcher, p. 4-14, 1986. Disponível em: http://fisica.uniud.it/URDF/masterDidSciUD/pdf/Shulman_1986.pdf. Acesso em: julho de 2017.

SILVA, D. K. O conhecimento da abordagem investigativa em aulas de Matemática na formação de Professores. Tese (doutorado). Florianópolis: UFSC, 2018. 270 p. no prelo. 